\title{
Study on Direct Current Electro-Deposition of Copper Nanowires in Anodic Alumina Membrane Pores
}

\author{
Lixia Ying ${ }^{1, *}$, Yue Xie ${ }^{1}$, Zhen Fu ${ }^{1}$, Hongrui Shi ${ }^{1}$ and Guixiang Wang ${ }^{2}$ \\ 1 Department of Mechanical Foundation, College of Mechanical and Electrical Engineering, \\ Harbin Engineering University, Harbin 150001, China; xieyue@hrbeu.edu.cn (Y.X.); \\ fuzhen0826@163.com (Z.F.); shihr@hrbeu.edu.cn (H.S.) \\ 2 Department of Metallic Material, College of Materials Science and Chemical Engineering, \\ Harbin Engineering University, Harbin 150001, China; wangguixiang@hrbeu.edu.cn \\ * Correspondence: yinglixia@hrbeu.edu.cn
}

Received: 5 May 2019; Accepted: 6 June 2019; Published: 11 June 2019

\begin{abstract}
Aluminum alloy plays an important role in industrial applications, but has a high friction coefficient and a high wear rate. On the basis of anodic oxidation treatment on an aluminum alloy surface, copper nanowires are deposited into the anodic alumina membrane pores by direct current (DC) electrolytic treatment to prepare a composite alumina membrane, which significantly improves the tribological properties of the aluminum alloy surface. In this process, in order to obtain a highly-ordered nanoporous alumina membrane with a thin enough barrier layer for further processing, after the first anodic oxidation in phosphoric acid $(0.3 \mathrm{~mol} / \mathrm{L})$, the obtained alumina membrane is modified by anodizing it in a phosphoric acid-ammonium hexafluorosilicate bath, in combination with a step-by-step voltage drop without oxide removal. By this method, the resistance of the modified alumina membrane is also reduced greatly, which facilitates the deposition of copper nanowires in the sulfate bath. It is found that the composite alumina membrane filled with copper nanowires has a low friction coefficient of about 0.25 and effectively improves the friction condition, giving the surface a self-lubricating property.
\end{abstract}

Keywords: aluminum alloy; anodic aluminum oxide; composite alumina membrane; modification treatment; copper nanowires

\section{Introduction}

Aluminum alloy is of upmost importance for its characteristics including its light weight, high specific strength, excellent electrical and thermal conductivity, as well as being easy to recycle $[1,2]$, but it has downsides, including a low hardness, a high friction coefficient about $0.4-0.8$, and high wear rates of about $10^{-4}-10^{-5} \mathrm{~mm}^{3} \mathrm{~m}^{-1}[3,4]$. Aluminum is a reactive metal whose surface is easily oxidized in the air to form a thin oxide layer. Moreover, the alumina film has two layers. The inner layer is the barrier layer, with an amorphous structure close to the matrix, and the outer layer is the porous oxide layer. This oxide layer protects aluminum and its alloys from atmospheric erosion. Therefore, anodization, a process by which electricity flows through an electrolyte, is widely applied in engineering to intentionally increase the thickness of the oxide layer [5]. As a porous film, the obtained anodic aluminum oxide (AAO) can not only solve the above problem, to a certain extent, but also has been widely used as a promising template, facilitating the growth of adjustable, self-organized, and highly ordered nanodots, nanorods, nanowires, nanotubes, and nanocomposite materials [6-9].

Different treatments of AAO can achieve different functional coatings. Athinarayanan Balasankar et al. utilized AAO to fabricate composite membranes which can be used in micro- and ultra-filtration in severe environments with a relatively high economic efficiency and large margins in the flow rate 
and breaking pressure [10]. Song et al. reported super slippery porous AAO surfaces have been fabricated by a simple and reproducible method. Such good materials, with excellent anti-corrosion properties, may be potential candidates for metallic application for anti-corrosion and in extreme environments [11]. Moonchan Lee et al. synthesized an AAO nanostructure, with a pore diameter of $80 \mathrm{~nm}$ (AAO80), directly on a quartz crystal substrate and deposited a thin gold film onto the $\mathrm{AAO} 80(\mathrm{Au} / \mathrm{AAO} 80)$, so the nanostructure surfaces were rendered hydrophobic via different chemical modifications to yield partially or fully superhydrophobic surfaces [12]. In the process of filling the AAO hole with nanowires, direct current electro-deposition is indeed an efficient way to obtain smooth and long nanowires. Naeem Ahmad et al. successfully fabricated well rounded, smooth, and elegantly elongated $\mathrm{Ni}_{76} \mathrm{Fe}_{24}$ nanowires inside the AAO templates at room temperature by cost effective DC electro-deposition [13]. Li et al. investigated the fabrication of CoNiGa ternary alloy nanowire arrays by simple DC electro-deposition into the AAO templates [14]. Muhammad Irfan et al. demonstrated that the fabrication of smooth and long Fe nanowire arrays inside nano-channels of an AAO template with a DC electro-deposition method at room temperature was feasible [15].

In this paper, in order to prepare the composite alumina membrane with a good lubrication performance and tribological properties, there are strict requirements for the length and uniformity of nanowires. So, we attempted to apply DC current instead of AC current for the deposition of copper nanowires. For the direct current electro-deposition, the influence of the barrier layers needs to be taken into account because of its high resistance, yet fluoride ions can improve the resistance characteristics of the barrier layers [16]. Herein, the barrier layers were modified by fluoride ions in combination with the step-by-step voltage drop in this paper. Finally, the deposition experiment of copper nanowires was carried out.

\section{Experimental}

\subsection{Pretreatment and Anodizing of Aluminum Alloy}

The experimental samples $(30 \mathrm{~mm} \times 50 \mathrm{~mm}$ ) were made from aluminum alloy sheets, $0.3 \mathrm{~mm}$ thick and with the nominal composition, as follows: $<0.35 \% \mathrm{Fe},<0.03 \% \mathrm{Mn},<0.03 \% \mathrm{Mg},<0.25 \% \mathrm{Si}$, $<0.05 \% \mathrm{Zn},<0.03 \% \mathrm{Ti},<0.05 \% \mathrm{Cu}$, and $>99.6 \% \mathrm{Al}$. The pretreatment process of the 1060 aluminum alloy samples (Shanghai Liangbai Aluminum Co., LTD, Shanghai, China) included surface smoothing, ultrasonic shock oil removal, alkali washing remove oxide layer, and pickling polishing. After the pretreatment, the anodic oxidation of aluminum alloy was carried out. In order to prepare anodic alumina film with ideal pore size, a DC constant current power supply, and a circulating water-cooling method were adopted in this paper. The film was prepared using a current density of $0.01 \mathrm{~A} / \mathrm{cm}^{2}$ for $1 \mathrm{~h}$ at $20^{\circ} \mathrm{C}$. The phosphoric acid $(0.3 \mathrm{~mol} / \mathrm{L})$ was selected as electrolyte. The aluminum alloy sample and a graphite plate were used as anode and cathode, respectively. The area of the cathode was $30 \%$ larger than that of the anode, to ensure current uniformity.

\subsection{Modification of Barrier Layer}

After anodic oxidation of the aluminum alloy, ammonium hexafluorosilicate was added to the electrolyte for further electrolysis, and the barrier layer was modified by a step-by-step voltage drop, which is a thinning treatment. Its principle is to utilize the proportional relation between the thickness of the barrier layer and the oxidation voltage intensity to gradually reduce the oxidation voltage and the thickness of the barrier layer to achieve the purposes of thinning and resistance reduction. In the traditional voltage drop method, with the decrease of the voltage value, the recovery speed of the current will become very slow. The whole process takes a long time and the traditional voltage drop method cannot effectively improve the resistance characteristics of the barrier layer. According to the study by Jagminas et al. on the preparation of an anodic alumina film using oxalic acid containing fluoride ions as an electrolyte [16], fluoride ions can improve the structure and conductivity characteristics of the barrier layer. Therefore, in this paper, fluoride ions in combination with a 
step-by-step voltage drop were utilized to modify the barrier layer. The specific voltage drop is as follows: The starting voltage is $130 \mathrm{~V}$, which is divided into 16 stages, in the first 9 stages, the value of each step-down is $10 \mathrm{~V}$, and in the last 7 stages, the step-down value of each stage is $5 \mathrm{~V}$. $\left(\Delta U_{1-9}=10 \mathrm{~V}\right.$, $\left.\Delta U_{10-16}=5 \mathrm{~V}\right)$. At each stage, when the current is stable, record the recovery time and proceed to the next stage.

The modification process adopted step-by-step voltage decrement in combination with adding the ammonium hexafluorosilicate. After each voltage drop, the voltage remained for a period of time, so that the current returned to a stable value. The times of each restoration were recorded and were compared with that of the traditional voltage drop method, as shown in Table 1. It was found that the recovery speed of the current was significantly faster with the participation of fluoride ions. The lower the voltage, the greater the difference of recovery speed, so the total time used in the experiment adopting the traditional voltage drop method was about $24 \mathrm{~min}$, but by adding fluoride ions in the electrolyte, the total experimental time was reduced to about $12 \mathrm{~min}$.

Table 1. Comparison of the time of the traditional voltage drop method and the traditional voltage drop method in combination with fluoride ions.

\begin{tabular}{ccccc}
\hline Voltage Drop (V) & $\mathbf{1 3 0 - 8 0}$ & $\mathbf{8 0 - 3 0}$ & $\mathbf{3 0 - 1 0}$ & $\mathbf{1 0 - 5}$ \\
\hline Fluorine-free voltage drop (min) & $3-5$ & $4-6$ & $5-8$ & $5-15$ \\
Fluorine-containing voltage drop (min) & $3-4$ & $3-4$ & $2-3$ & $2-3$ \\
\hline
\end{tabular}

\subsection{Deposition of Copper Nanowires}

The porous alumina film, obtained by the modified treatment above, was electrolyzed in an electrolyte containing copper ions to prepare composite alumina film. Considering the stable chemical properties and that it is easy to deposit, soft metal copper was chosen as the filling material in the experiment for preparing composite alumina film. In addition, it is also hoped that copper nanowires can optimize the friction surface, giving superficies certain self-repairing and self-lubricating properties.

The bath was set as follows, the graphite plate and aluminum oxide plate were used as the anode and cathode, respectively, and a magnetic stirrer was used in the electrolyte to improve the concentration of ions near the cathode. The bath composition and plating parameters are listed in Table 2. Copper sulfate was used as the main salt, magnesium sulfate as the deputy salt, boric acid as the $\mathrm{pH}$ buffer, and the $\mathrm{pH}$ value of the electrolyte solution was maintained at 3.0-4.0. If the $\mathrm{pH}$ value is less than 3 , the content of hydrogen ions in the solution increases, and its capacity for discharge is stronger than that of copper ions. Conversely, when the $\mathrm{pH}$ value is above 4 , the content of hydroxyl ions in the solution will increase, so it is easy to form copper hydroxide, which is averse to the deposition of copper nanowires. Furthermore, considering the deposition rate and other factors, the optimal deposition voltage range is $3-4 \mathrm{~V}$.

Table 2. Composition of electroplating bath and parameters.

\begin{tabular}{cc}
\hline Parameters & Concentration \\
\hline $\mathrm{CuSO}_{4} \cdot 5 \mathrm{H}_{2} \mathrm{O}$ & $20(\mathrm{~g} / \mathrm{L})$ \\
$\mathrm{MgSO}_{4}$ & $5(\mathrm{~g} / \mathrm{L})$ \\
$\mathrm{H}_{2} \mathrm{BO}_{3}$ & $5(\mathrm{~g} / \mathrm{L})$ \\
$\mathrm{C}_{12} \mathrm{H}_{25} \mathrm{SO}_{4} \mathrm{Na}$ & $2(\mathrm{~g} / \mathrm{L})$ \\
Temperature & $20\left({ }^{\circ} \mathrm{C}\right)$ \\
pH & $3.0-4.0$ \\
Time & $10-30(\mathrm{~min})$ \\
\hline
\end{tabular}

In the experiment for the deposition of copper nanowires, the current vs. time curve of alumina membrane at the deposition voltage of $3 \mathrm{~V}$ was recorded, as shown in Figure 1. It was found that in the first twenty minutes of the experiment, the deposition current was relatively stable, but as 
the deposition length of copper nanowires in the nanotubes increased, the current curve showed an upward trend with the increase of deposition time. It might be that the distance of free ions outside the nanotubes to the deposition position was closer, the ions diffused faster, and the resistance caused by concentration difference polarization decreased.

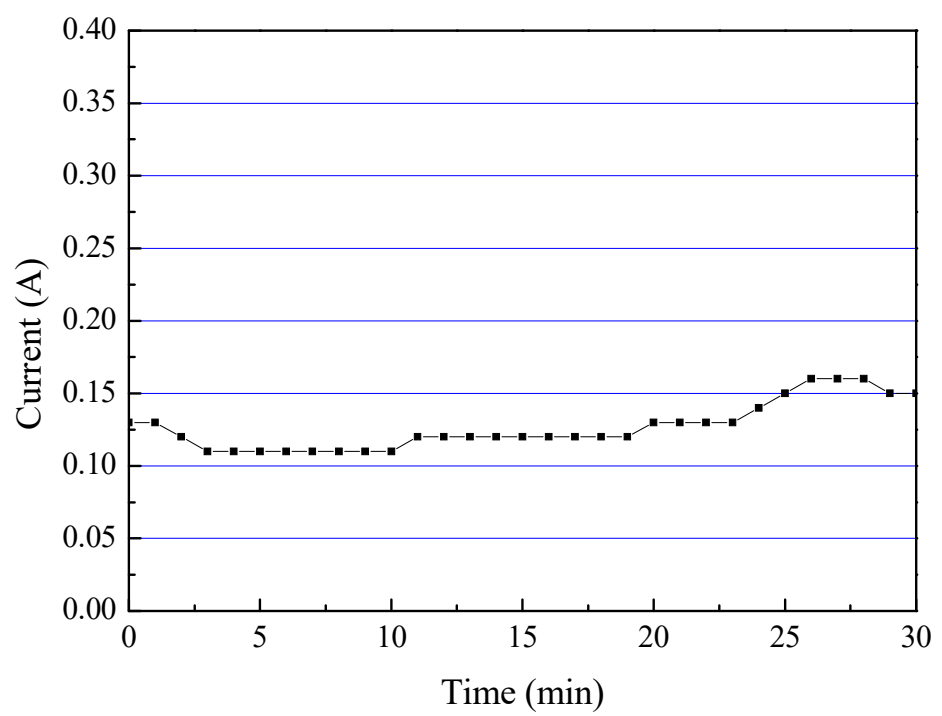

Figure 1. Current vs. time curve of modified alumina film in the experiment of copper nanowires deposition.

\subsection{Analytical Test}

Surface morphology and the cross section of the sample were examined by Hitachi S-4800/350 scanning electron microscopy (SEM, FEI, Hillsboro, OR, USA). As the scanning electron microscope requires the high conductivity of the sample, the Gatan682 etching and coating instrument was utilized to spray gold on the surface of the sample to enhance its conductivity. An X-ray diffractometer (TD-3500, TongDa, Liaoning, China) was also used to determine the phase present. The tribological properties of the coatings were characterized by a friction-abrasion testing machine (SFT-2M, ZhongKe-kaihua, Lanzhou, China) at a load of $100 \mathrm{~g}$ and speed of $100 \mathrm{rpm}$, with a wear time of $20 \mathrm{~min}$. The friction counterpart was a GCr15 steel ball of $5 \mathrm{~mm}$ in diameter and the friction-wear behavior of the composite alumina film was compared with that of the alumina film.

\section{Results and Discussion}

\subsection{Structure of Anodic Alumina Membrane}

Figure 2 shows the surface and cross of the anodic alumina film prepared in this paper. It can be seen from the figure that the surface of colorless alumina film is porous with an average pore diameter of about $200 \mathrm{~nm}$ and a film thickness more than $20 \mu \mathrm{m}$. The hexagonal pore with basically the same diameter, arranged orderly, as well as the parallel nanotubes, grow perpendicular to the surface and there is a barrier layer with a thickness of about $500 \mathrm{~nm}$ between the multi-hole oxide layer and the aluminum substrate. The pore size and pore distribution of the obtained anodic alumina film are suitable for the deposition of copper nanowires, but, as mentioned above, further modification of the barrier layer is needed to make its resistance more consistent with the experimental requirements. 


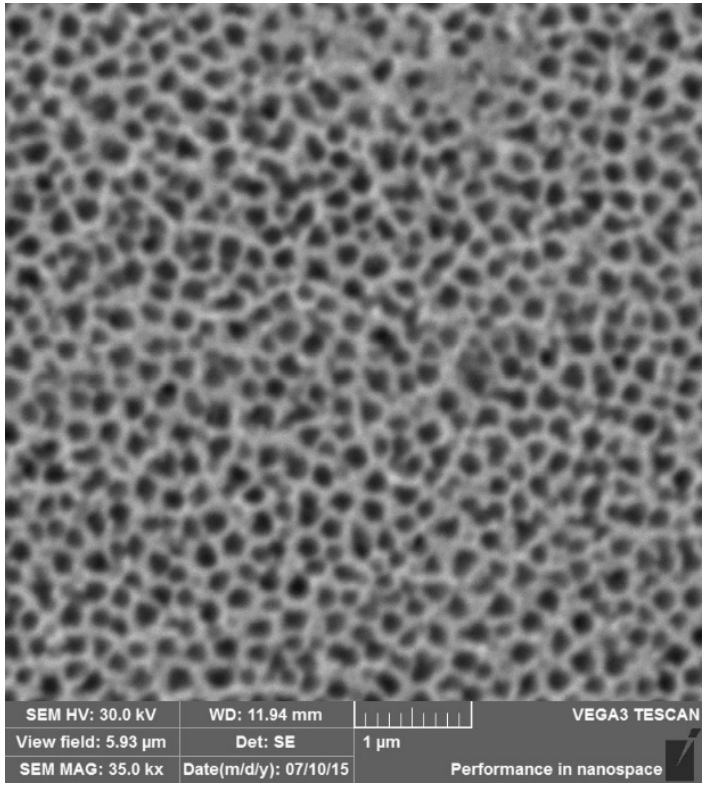

(a)

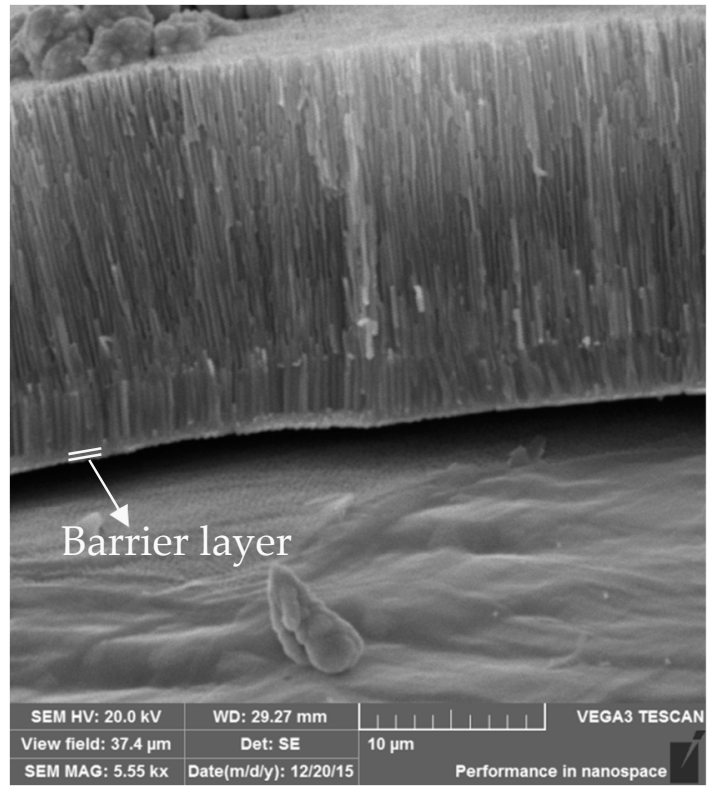

(b)

Figure 2. Electron micrograph of anodic alumina film: (a) Surface and (b) Cross.

\subsection{Analysis and Structure of the Composite Alumina Membrane}

The cross-sectional scanning electron microscopy photographs of the composite alumina membrane are shown in Figure 3. Figure 3a shows the cross-section morphology before deposition, while Figure $3 b, c$ show the cross-section morphology after deposition for 10 and $30 \mathrm{~min}$, respectively. It can be seen in Figure 3a that the barrier layer has almost disappeared after modification. Comparison with Figure 3a shows that, at $10 \mathrm{~min}$ of the deposition experiment, the nanowires of about $11.9 \mu \mathrm{m}$ appear from the bottom, and the nanowires are pulled out of the nanotubes due to tearing during the cross-section preparation. However, as can be seen from Figure 3c, nanowires are distributed throughout the nanotubes after the deposition. At the whole progress, the growth rate is relatively uniform and the growth length increases with the increase of time.

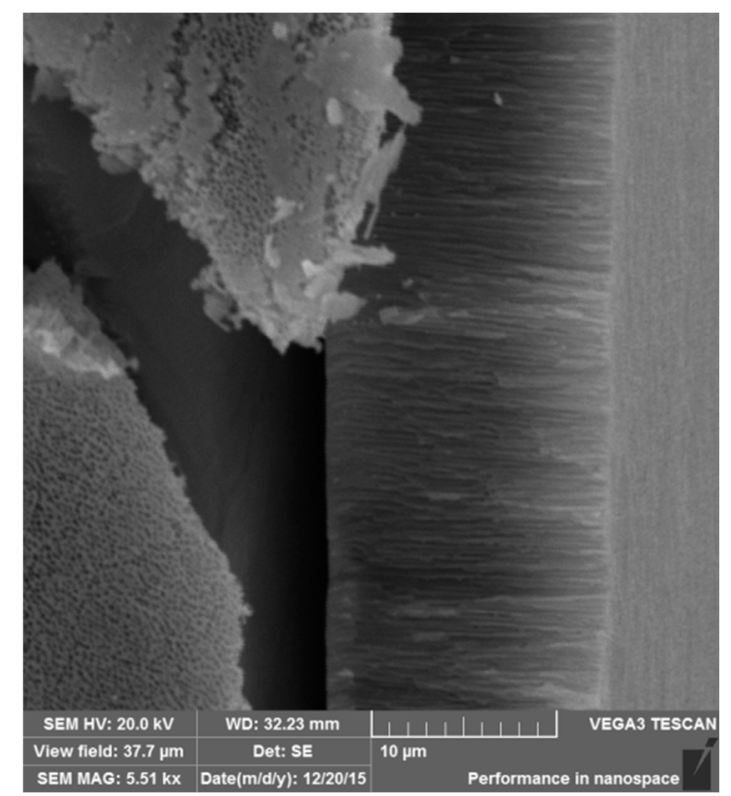

(a)

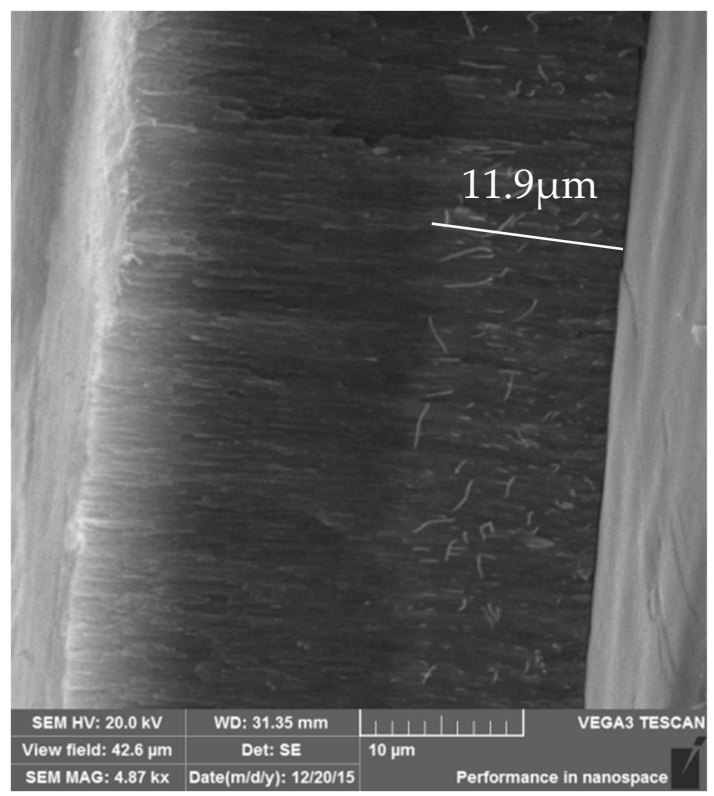

(b)

Figure 3. Cont. 


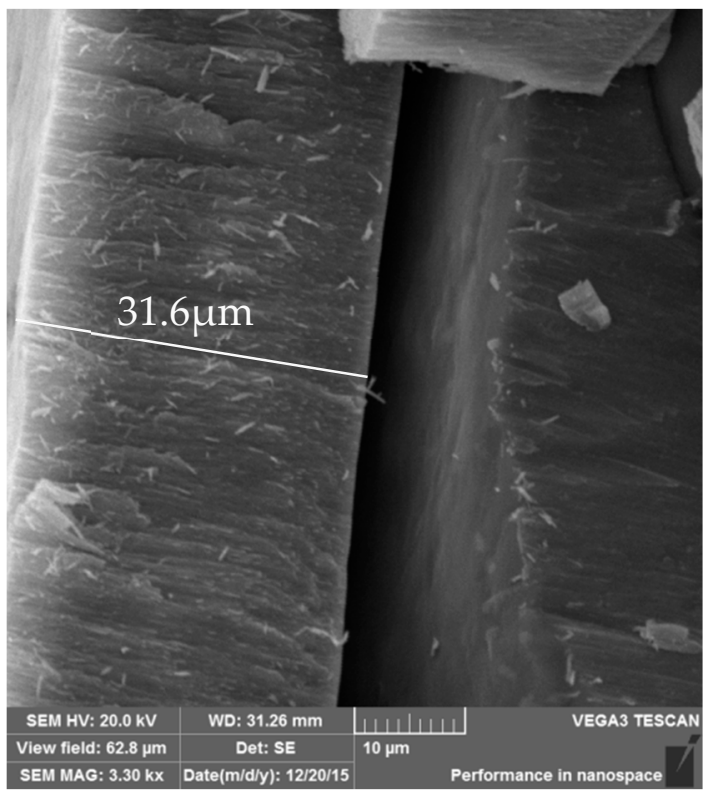

(c)

Figure 3. Cross-sectional electron microscopy photographs of the modified alumina film at different deposition times (a) $0 \mathrm{~min}$; (b) $10 \mathrm{~min}$; and (c) $30 \mathrm{~min}$.

With 30 min of deposition, the surface topography and cross-section topography of composite alumina film filled with copper nanowires at larger magnification are shown in Figure 4. Figure 4a shows the superficial characteristics of the nanowires after depositing and the diameter of the copper nanowires are about $200 \mathrm{~nm}$. As can be seen from Figure 4b, due to the limitation effect of nanotubes, the growth of nanowires is uniform and orderly, with a high degree of filling from the bottom to the surface.

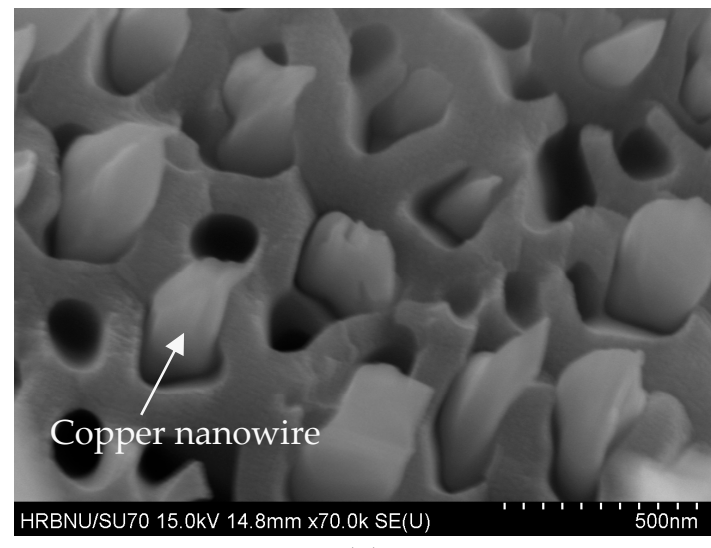

(a)

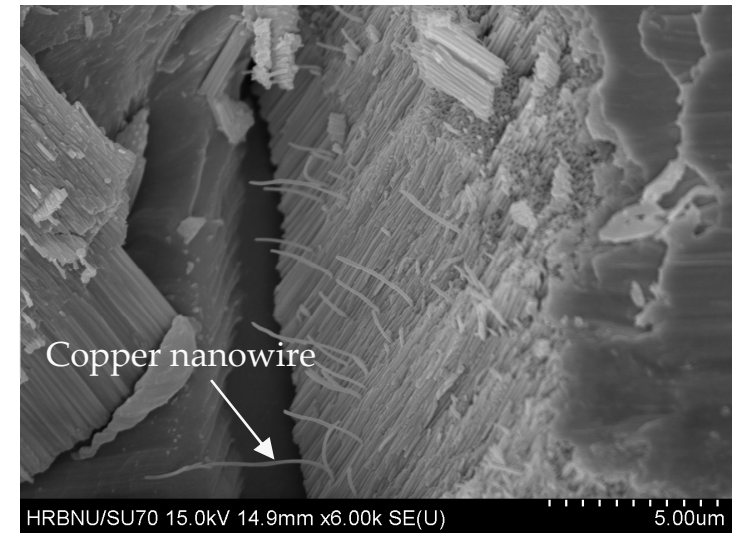

(b)

Figure 4. Electron microscopy photographs of composite alumina film filled with copper nanowires (a) Surface and (b) Cross.

XRD was utilized to study the composite alumina film, and the results are shown in Figure 5. In Figure 5a,b, the apparent crystal absorption peak of $\mathrm{Al}$ can be seen in the XRD analysis diagram, reflecting the crystal state of the aluminum matrix. By comparing the XRD of composite alumina film and anodic alumina film, the copper absorption peak in XRD of composite alumina film illustrates the successful filling of copper nanowires. During the growth of copper nanowires, a (111) crystallographic plane was selected preferentially. The other three crystallographic plane absorption peaks are (111), (200), and (220) peaks of $\mathrm{Cu}$, of which the intensity of the (111) crystallographic plane absorption peak 
is over 10,000 cps. Based on the above results, the structure of the composite alumina membrane can be determined, and it is crystal copper nanowires, preferably grown along the (111) crystallographic plane, in an amorphous alumina membrane.

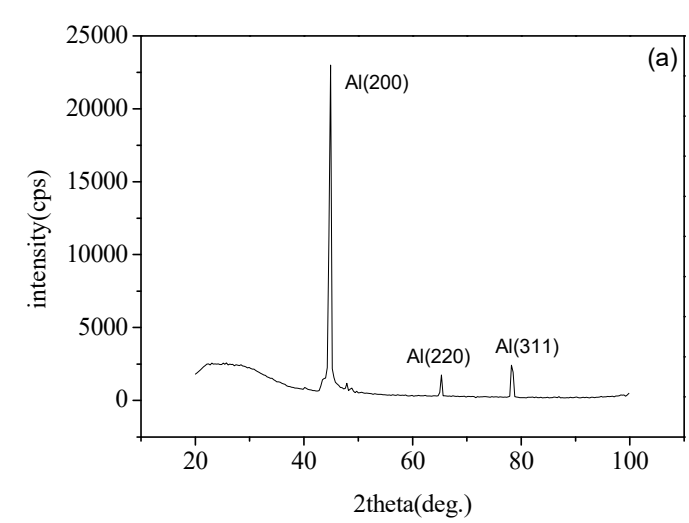

(a)

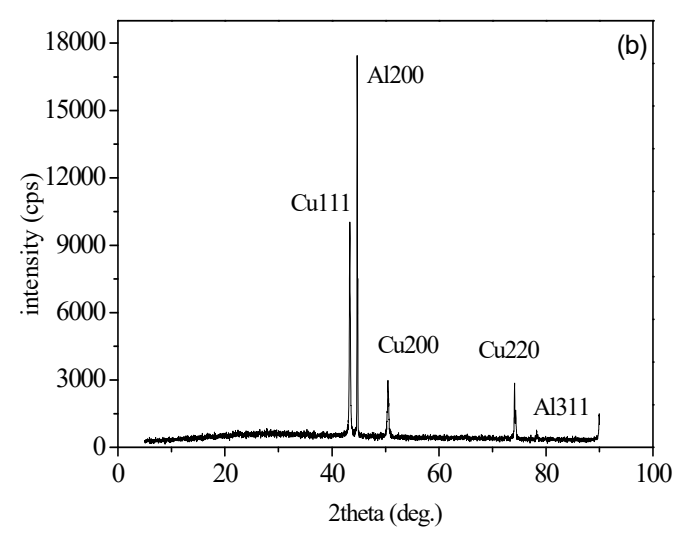

(b)

Figure 5. XRD analysis diagram of (a) anodic alumina film and (b) composite alumina film filled with copper nanowires.

The growth model of the composite alumina membrane is established as shown in Figure 6, and Figure $6 \mathrm{a}-\mathrm{c}$ correspond to Figure $3 \mathrm{a}-\mathrm{c}$, respectively. The growth of nanowires begins from the bottom in the form of electro-deposition. Due to the difference in the shape and size of the nanotubes, as well as the difference in the performance of the barrier layer, the growth rates of nanowires in different holes are different. The nanowires basically grow to the surface about 30 min into the experiment and they continue to grow. At this time, the effect of the nanotubes on the diffusion of ions disappears and the current reaches its maximum.

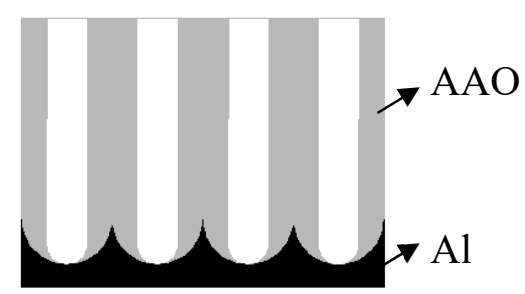

(a)

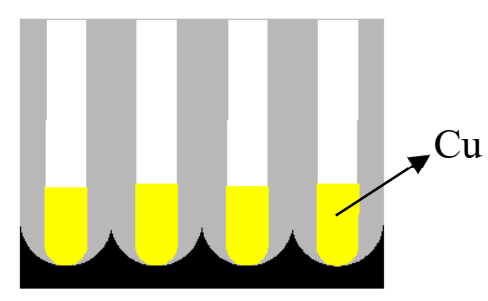

(b)

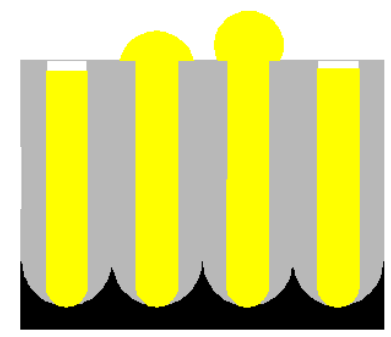

(c)

Figure 6. Growth model of composite alumina film (a) $0 \mathrm{~min}$, (b) $10 \mathrm{~min}$, and (c) $30 \mathrm{~min}$

\subsection{Tribological Properties of Composite Alumina Membrane}

Figure 7 shows curves of the coefficient of friction (COF) of the coating versus the sliding time. Compared with that of alumina membrane (0.7-0.8), the friction coefficient of the composite alumina membrane decreases to about 0.25 . Furthermore, after a certain period of testing time, the friction coefficient of the composite alumina membrane becomes more and more steady. On the contrary, the friction coefficient of alumina film fluctuates greatly during the whole process. 


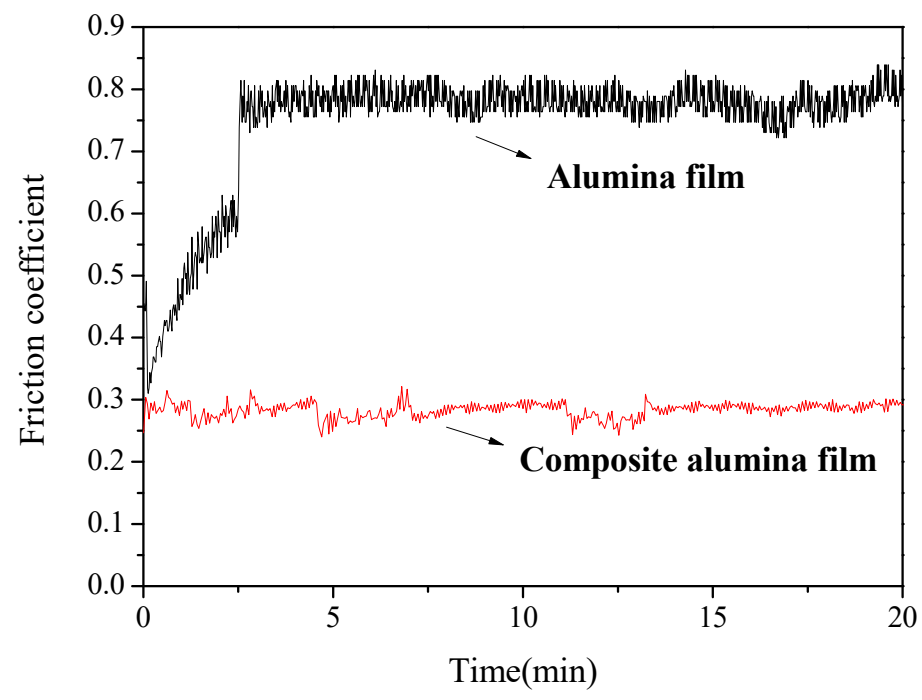

Figure 7. Friction coefficient of the composite alumina film and alumina film.

Figure 8 shows worn surfaces of the alumina film with and without copper, respectively. During wear testing, the failure of the alumina film without $\mathrm{Cu}$ involved roughening, tearing, and spalling (Figure 8a). A large number of debris can also be observed at the edge of the track. Those indicate serious adherence and abrasive wear. However, the friction surface of the composite alumina film becomes smoother than that of the surface outside contact area. Only slightly crushed and adhesive marks of wear are observed. Simultaneously, the widths of worn tracks of the alumina film and composite alumina film are $609.75 \pm 6.12 \mu \mathrm{m}$ and $333.33 \pm 5.56 \mu \mathrm{m}$, respectively. As illustrated, the wear tracks of the composite alumina film are narrower than those of the pure alumina film, demonstrating that the filling of copper nanowires can enhance the wear resistance of the alumina film.

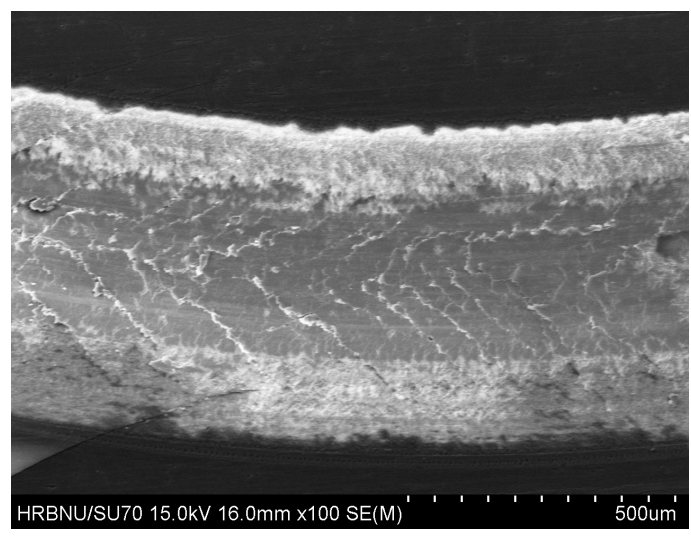

(a)

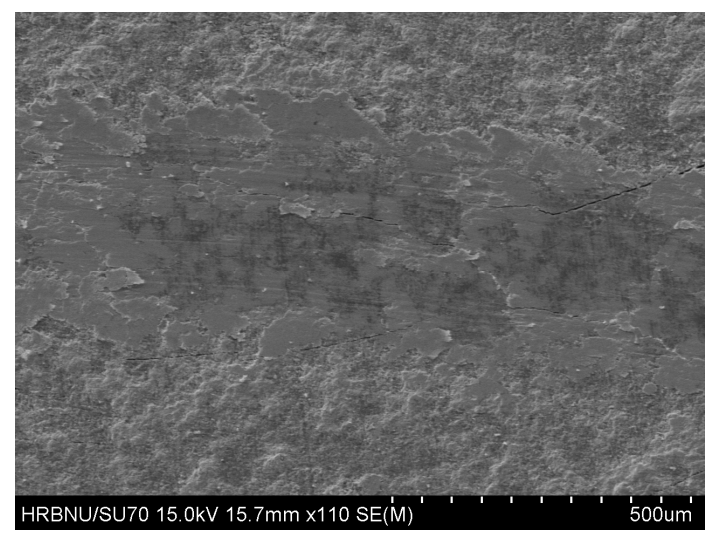

(b)

Figure 8. Electron microscopy photographs of wear marks: (a) Alumina film and (b) composite alumina film.

After comprehensive comparison of the alumina film and the composite alumina film, it was found that they have certain differences in friction, wear form, and mechanism. Due to the alumina membrane with the micro-hole structure, the real contact points are actually distributed on the wall of the hole. In the process of friction, the wall of the hole is forced to suffer a deformation and transverse damage, exacerbated coating failure. So, the wear form of the alumina film surface is mainly adherence and abrasive wear. However, the friction surface of the composite alumina film is very smooth and does not appear to be affected by the above abrasions. This is because copper is subjected to friction and compression during the frictional process, precipitating out from the micro-pores and spreading 
out over the contact area. In addition, due to the low hardness and shear strength of copper, it can effectively reduce the friction coefficient. With the progress of friction, the copper film dragged on the surface of the friction pair will also wear out, adhere, and fall off. However, the surface micro-pores can be regarded as the storage vessel of copper, and new copper will be squeezed out and dragged on the surface. So, the soft metal copper deposited in the micro-pores is dragged onto the surface by friction and extrusion, forming a layer of solid lubrication film, which plays a role in anti-friction and lubrication. At the same time, the pores are filled with copper. The overall loading area and strength of the friction surface are also increased, which leads to higher wear resistance.

From what has been discussed above, all the evidence proves that composite alumina film effectively improves the friction condition, giving the surface a certain self-lubricating function.

\section{Conclusions}

- On the basis of the traditional modification of barrier layers, ammonium hexafluorosilicate, in combination with step-by-step voltage decrement, was used to modify alumina membrane barrier layers and obtain barrier layers with reduced resistance. It was found that the addition of fluoride ions had a remarkable effect on the current change in the process of voltage drop. Compared with the traditional modification of barrier layers, the improved method in this paper is simple in operation and short in processing time and the obtained barrier layers can fully meet the requirement of the resistance of the DC electro-deposition in the alumina membrane pores.

- Copper nanowires were deposited in alumina membrane pores to prepare the composite alumina membrane using DC electro-deposition. SEM and XRD were used to analyze the morphology and crystallization of the composite alumina membrane so its structure could be determined, which is crystal copper nanowires that grow, preferably, along the (111) crystallographic plane in amorphous alumina membrane. The growth pattern of copper nanowires from the bottom of the hole to the top is deduced according to electron microscopy photographs at different growth times and at different sections.

- The composite alumina membrane has a low and stable friction coefficient of about 0.25. Additionally, it effectively improves the friction condition, giving the surface a certain self-lubricating function, which proves that this method of improving the tribological properties of an aluminum alloy surface is feasible.

Author Contributions: Conceptualization, L.Y. and G.W.; Methodology, L.Y. and G.W.; Formal Analysis, L.Y. and H.S.; Investigation, L.Y. and Y.X.; Validation, L.Y.; Writing-Original Draft Preparation, L.Y. and Y.X.; Writing-Review \& Editing, L.Y., Y.X. and Z.F.

Funding: This research was funded by the Natural Science Foundation of Heilongjiang Province, China (JJ2019LH1520).

Conflicts of Interest: The authors declare no conflict of interest.

\section{References}

1. Mandal, P.; Mondal, S.C. Investigation of electro-thermal property for Cu-MWCNT composite coating on anodized 6061 Aluminium Alloy. Appl. Surf. Sci. 2018, 454, 138-147. [CrossRef]

2. Zhang, J.L.; Song, B.; Wei, Q.S.; Bourell, D.; Shi, Y.S. A review of selective laser melting of aluminum alloys: Processing, microstructure, property and developing trends. J. Mater. Sci. Technol. 2018, 35, $270-284$. [CrossRef]

3. Zhang, J.; Alpas, A.T. Wear regimes and transitions in $\mathrm{Al}_{2} \mathrm{O}_{3}$ particulate-reinforced aluminum alloys. Mater. Sci. Eng. 1993, 161, 273-284. [CrossRef]

4. Bai, B.N.P.; Ramasesh, B.S.; Surappa, M.K. Dry sliding wear of A356-Al-SiC composites. Wear 1992, 157, 295-304. [CrossRef]

5. Sooksaen, P.; Chulasinont, O.; Janmat, P.; Thovasakul, W. Chemical treatment on aluminum alloy for hydrophobic surfaces. Mater. Today Proc. 2017, 4, 6528-6533. [CrossRef] 
6. Jani, A.M.M.; Losic, D.; Voelcker, N.H. Nanoporous anodic aluminium oxide: Advances in surface engineering and emerging applications. Prog. Mater. Sci. 2013, 58, 636-704. [CrossRef]

7. Lee, W.; Ji, R.; Gösele, U.; Nielsch, K. Fast fabrication of long-range ordered porous alumina membranes by hard anodization. Nat. Mater. 2006, 5, 741-747. [CrossRef] [PubMed]

8. Maejima, M.; Saruwatari, K.; Takaya, M. Friction behaviour of anodic oxide film on aluminum impregnated with molybdenum sulfide compounds. Surf. Coat. Technol. 2000, 132, 105-110. [CrossRef]

9. Michalska-Domanska, M.; Norek, M.; Stepniowski, W.J.; Budner, B.A. Fabrication of high quality anodic aluminum oxide (AAO) on low purity aluminum-A comparative study with the AAO produced on high purity aluminum. Electrochim. Acta. 2013, 105, 424-432. [CrossRef]

10. Athinarayanan, B.; Jeong, D.Y.; Kang, J.H.; Koo, B.H. Fabrication of nanoporous aluminum-oxide composite membranes. J. Korean Phys. Soc. 2015, 67, 1970-1976. [CrossRef]

11. Song, T.; Liu, Q.; Liu, J.; Yang, W.; Chen, R.; Jing, X.; Takahashi, K.; Wang, J. Fabrication of super slippery sheet-layered and porous anodic aluminium oxide surfaces and its anticorrosion property. Appl. Surf. Sci. 2015, 355, 495-501. [CrossRef]

12. Lee, M.; Lee, S.; Yim, C.; Jeon, S. Surface wetting of superhydrophobic aluminum oxide nanostructures investigated using the fiber-optic spectrometer and quartz crystal microbalance. Sens. Actuators B 2015, 220, 799-804. [CrossRef]

13. Ahmad, N.; Saeed, A.; Khan, S.; Hassan, F.; Li, W.J.; Shah, S.A.; Majid, A.; Han, X.F. Investigation of easy axis transition and magnetodynamics in $\mathrm{Ni}_{76} \mathrm{Fe}_{24}$, nanowires and $\mathrm{Ni}_{77} \mathrm{Fe}_{23}$, nanotubes synthesized by DC electrodeposition. J. Alloy. Compd. 2017, 725, 123-128. [CrossRef]

14. Li, W.J.; Khan, U.; Irfan, M. Fabrication and magnetic investigations of highly uniform CoNiGa alloy nanowires. J. Magn. Magn. Mater. 2017, 432, 124-128. [CrossRef]

15. Irfan, M.; Khan, U.; Li, W.; Adeela, N.; Javed, K.; Han, X.F. Magnetic investigations of post-annealed metallic Fe nanowires via electrodeposition method. Mater. Lett. 2016, 180, 235-238. [CrossRef]

16. Jagminas, A.; Vrublevsky, I.; Kuzmarskytè, J.; Jasulaitienė, V. Composition, structure and electrical properties of alumina barrier layers grown in fluoride-containing oxalic acid solutions. Acta Mater. 2008, 56, 1390-1398. [CrossRef]

(C) 2019 by the authors. Licensee MDPI, Basel, Switzerland. This article is an open access article distributed under the terms and conditions of the Creative Commons Attribution (CC BY) license (http://creativecommons.org/licenses/by/4.0/). 